\title{
Surgical Application of the Suboccipital Subtonsillar Approach to Reach the Inferior Half of Medulla Oblongata Tumors in Adult Patients
}

\author{
Alejandra T. Rabadán ${ }^{1 *}$, Alvaro Campero ${ }^{2}$ and Diego Hernández ${ }^{1}$ \\ ${ }^{1}$ Division of Neurosurgery, Institute of Medical Research A. Lanari, University of Buenos Aires, Buenos Aires, Argentina, \\ ${ }^{2}$ Department of Neurosurgery, Hospital Padilla, Tucumán, Argentina
}

\section{OPEN ACCESS}

Edited by:

Eberval Figueiredo,

Hospital das Clínicas da Universidade

de São Paulo, Brazil

Reviewed by:

Louis J. Kim

University of Washington School of

Medicine, USA

Leonardo Welling,

State University of Ponta Grossa,

Brazil

Feres Chaddad,

Federal University of São Paulo,

Brazil

*Correspondence:

Alejandra T. Rabadán

alejandrarabadan@speedy.com.ar

Specialty section:

This article was submitted to

Neurosurgery,

a section of the journal

Frontiers in Surgery

Received: 17 October 2015

Accepted: 24 December 2015

Published: 13 January 2016

Citation:

Rabadán AT, Campero A and Hernández D (2016) Surgical Application of the Suboccipital

Subtonsillar Approach to Reach the Inferior Half of Medulla Oblongata

Tumors in Adult Patients.

Front. Surg. 2:72.

doi: 10.3389/fsurg.2015.00072
Medulla oblongata $(\mathrm{MO})$ tumors are uncommon in adults. Controversies about their treatment arise regarding the need for histological diagnosis in this eloquent area of the brain, weighing benefits of a reliable diagnosis, and the potential disadvantages of invasive procedures. As a broader variety of pathological findings could be found in this localization, the accurate histopathological definition could not only allow an adequate therapy but also can prevent the disastrous consequences of empiric treatments. There are few publications about their surgical management and all belongs to small retrospective cohorts. In this scenario, we are reporting two patients with exophytic or focal lesions in the inferior half of the medulla, who underwent surgery by suboccipital midline subtonsillar approach. This approach was not specifically described to reach $\mathrm{MO}$ before, and we found that the lesions produced a mild elevation of the tonsils providing a wide surgical view from the medulla to the foramen of Luchska laterally, and up to the middle cerebellar peduncle, offering a wide and safe access.

Keywords: subtonsillar approach, medulla oblongata, tumors, brainstem, surgery

\section{INTRODUCTION}

Brainstem tumors are infrequent in adult patients. Median age of presentation is the fourth decade of life, and overall survival is about $54-64$ months. They represent $<2 \%$ of all brain tumors in epidemiological data (1). Those located exclusively in the medulla oblongata (MO) are still more sporadic, so that few reports of purely medulla tumors ranged from 0 to $21 \%$ among the brainstem tumors reported series (1-8) (Table 1).

There are isolated reports of small surgical experiences dealing with direct surgery in this particular CNS region. Although most of them reported satisfactory results, others described that postoperative neurological deterioration was common and suggested that surgery is of questionable benefit (9-18).

Abbreviations: BS, brainstem; CNS, central nervous system; CSF, cerebrospinal fluid; MO, medulla oblongata; MRI, magnetic resonance imaging; PICA, posterior inferior cerebellar artery. 
TABLE 1 | Relation between number of tumors of the brainstem and medulla oblongata in adults.

\begin{tabular}{lcc}
\hline Reference & No. of BS tumors & No. of MO tumors \\
\hline Grigsby et al. (2) & 32 & 3 \\
Shieve et al. (5) & 19 & 0 \\
Guiney et al. (4) & 21 & 0 \\
Landolfi et al. (3) & 19 & 4 \\
Selvapandian et al. (6) & 30 & 0 \\
Guillamo et al. (1) & 48 & 12 \\
Salmaggi et al. (8) & 34 & 6 \\
\hline
\end{tabular}

Regarding the type of mass lesions that can be found in adults, a diversity of histopathological findings has been reported, such as high-grade and low-grade astrocytomas, anaplastic and low-grade oligodendrogliomas, ependymomas, gangliogliomas, DNT's, metastases, granulomas, lymphomas, infection, inflammatory diseases, and pseudotumoral lesions as tumefactive demyelinating diseases $(1,19,20)$. These oncological and nononcological entities require specific treatment and obviously have a very different prognosis.

Therefore, controversies arise regarding the need for histological diagnosis in this eloquent area of the brain, weighing benefits of a reliable diagnosis and the potential disadvantages of invasive procedures. In this scenario, recommendation of the surgical management in adult patients cannot be defined with an appropriate level of evidence. Meanwhile, the contribution of our two cases experience dealing with uncommon tumors of the MO can provide more information for the surgical decision making process.

\section{PATIENTS AND METHODS}

\section{Report of Cases Case 1}

A 41-year-old woman had a 6-month history of headache, vertigo, unsteadiness, and persistent cough. At admission, she had 90 points Karnofsky performance status (KPS). The patient did not have a relevant medical history and her clinical work up was normal. Funduscopy was normal. T1-weighted MRI scans showed an exophytic hypointense and homogenous mass in the left $\mathrm{MO}$ without gadolinium enhancement. Complete MRI scans of the entire neuroaxis were unremarkable. The suspected preoperative diagnosis was low-grade glioma or ependymoma, according to the more common lesions with its radiographic features in this CNS localization. The intraoperative biopsy demonstrated a tumor composed of cells like ependymoma and astrocytes. This finding supported the complete excision of the lesion. The definitive diagnosis was subependymoma.

Postoperatively, the patient presented transient dysphagia, which recovered after a few months rehabilitation period. Neurological symptoms relieved significantly in the long-term follow-up in comparison to preoperative status; however, dizziness episodes still appear occasionally. The subependymoma is a low-grade glioma, with a well-known good survival prognosis, and low chances of recurrence when complete resection is
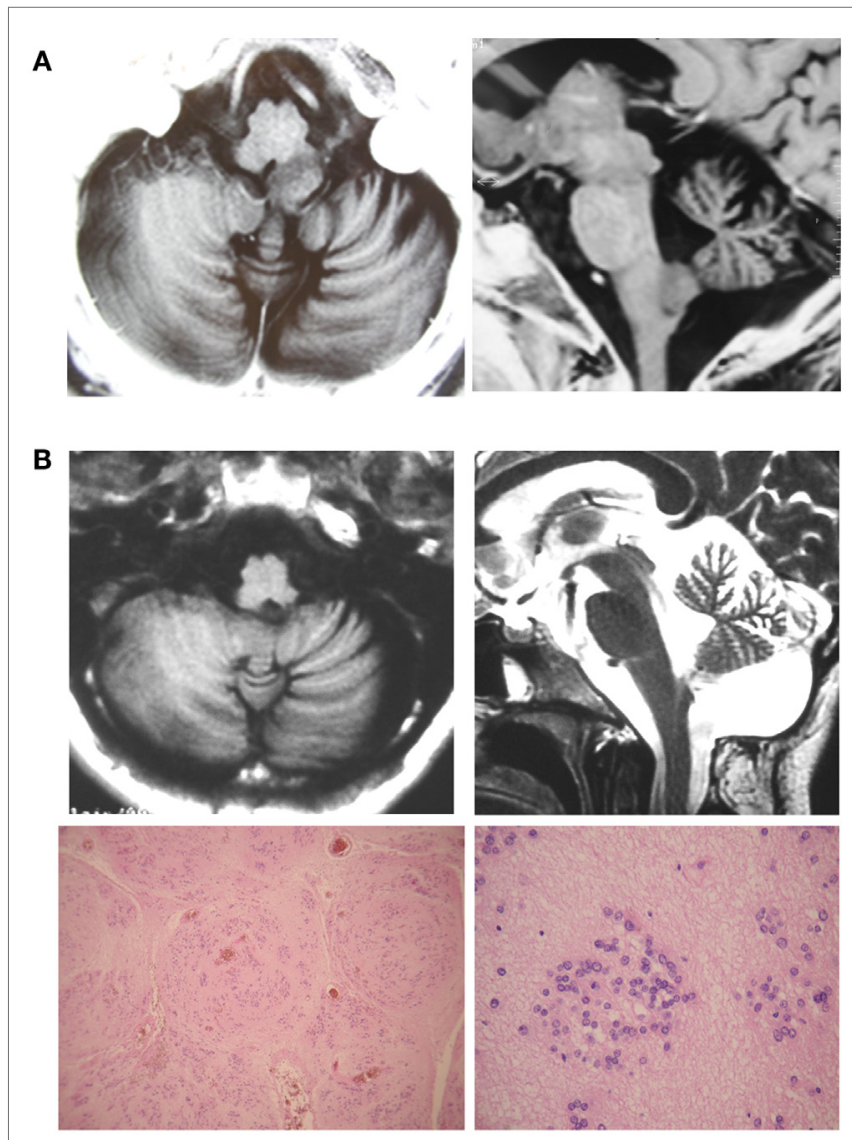

FIGURE 1 | (A) Case 1. Preoperative T1-weighted brain MRI scan showed a hypointense and homogenous mass within the left $\mathrm{MO}$ without Gadolinium enhancement. (B) The postoperative T1-weighted brain MRI scan showed complete resection of the tumor.

accomplished; therefore, the patient did not required additional therapy after surgery (Figures 1A,B).

\section{Case 2}

A 30-year-old man had a 2-month history of headaches, vomiting, gait ataxia, dysphonia, dysphagia, and urinary incontinence presenting a 60 KPS. T1-weighted cerebral MRI scans showed a wider medulla due to a hypointense heterogeneous mass with necrosis or polimicrocysts. Gadolinium-enhanced T1-weighted MRI scans demonstrated a heterogeneously enhancing mass. MRI scans of the complete neuroaxis were unremarkable. The patient had had a suprasellar germ cell tumor in childhood that was treated with radiotherapy. He did well in the long-term follow-up, without evidence of recurrence during the last 20 years. Blood markers as alfafetoprotein (AFP), $\beta$-human chorionic growth factor (BHCG), and embryonic-carcinoid antigen (ECA) levels were within the normal range. Lumbar puncture to obtain CSF biochemical markers (AFP, BHCG, and ECA) or pathological cells was inadvisable because of the tumor extension and the presence of intracranial hypertension.

A direct approach was performed with the presumptive diagnosis of a new CNS lesion or a progression of the previous disease. 
The intraoperative finding demonstrated a germ cell tumor and, as this type of tumor is very sensitive to oncological treatment, only a subtotal resection was performed, No surgical complications were observed. The neurological status dramatically improved postoperatively to $90 \mathrm{KPS}$; it could probably be related to the evacuation of the cyst component of the tumor and the posterior fossa decompression. Then, he received chemotherapy and radiation therapy (Figures 2A,B).

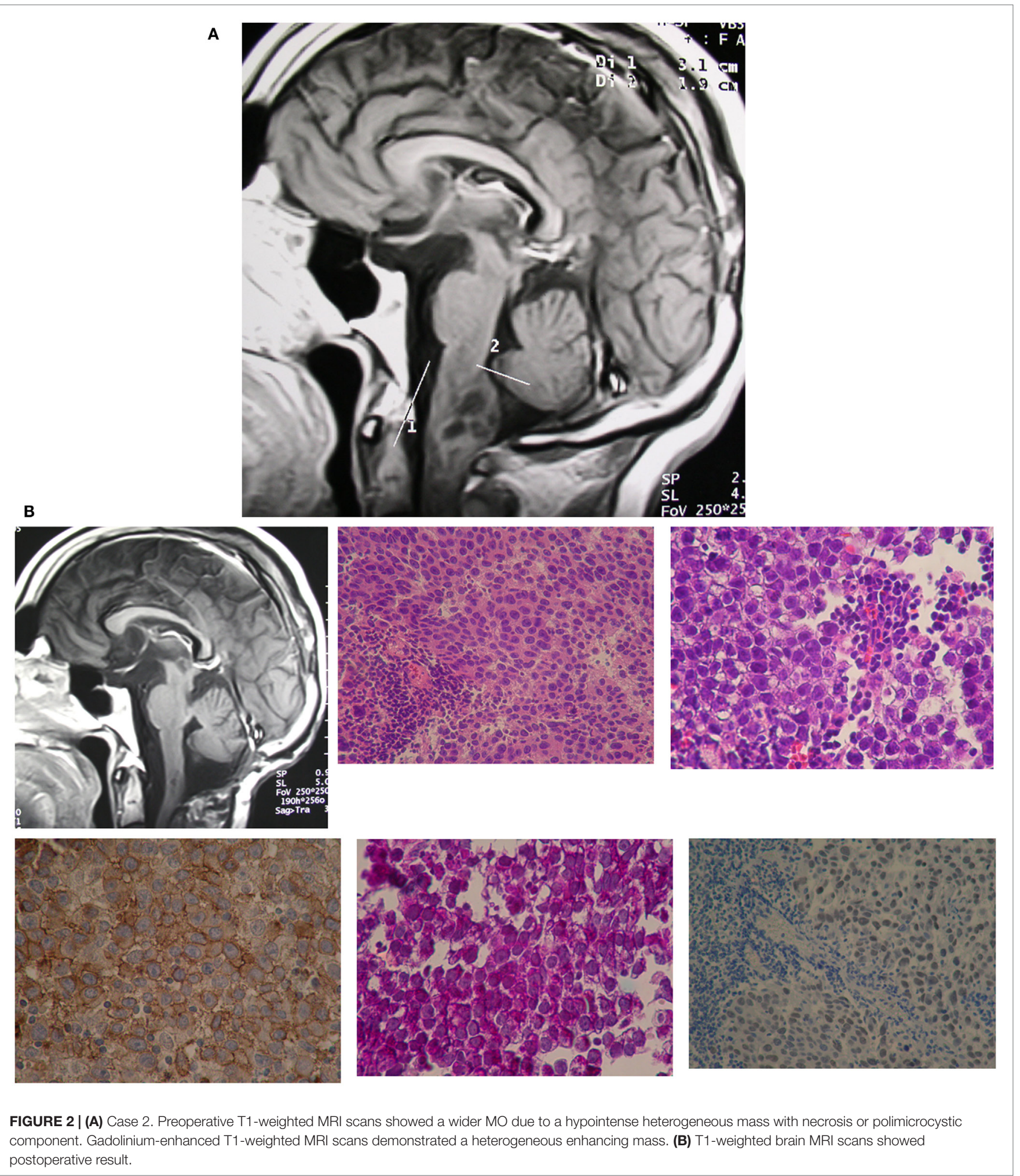



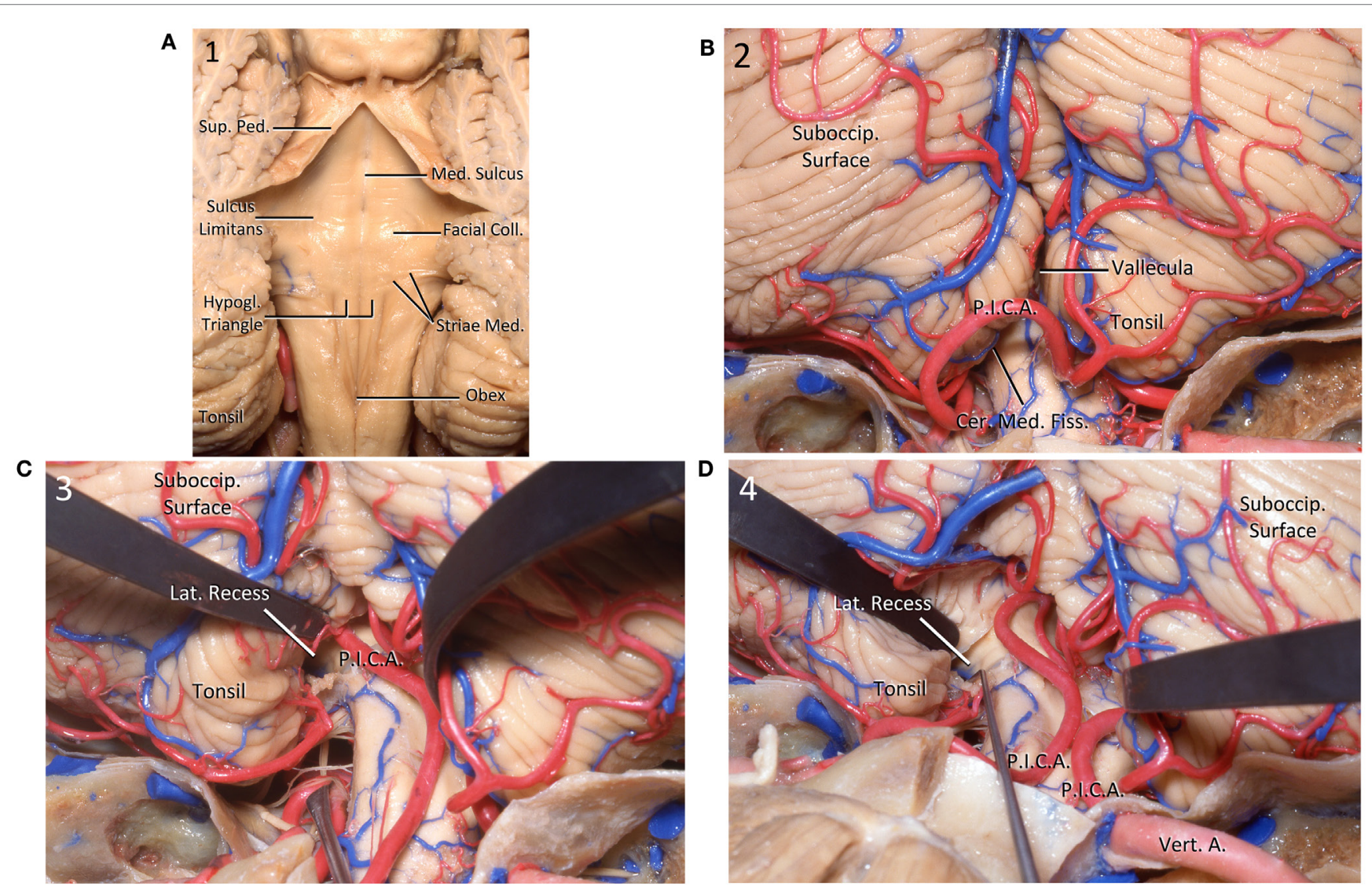

FIGURE 3 | (A) Posterior view of the floor of the IV ventricle. The floor is divided in the midline by the median sulcus and craniocaudally into pontine, junctional, and medullary parts. Coll., colliculus; Hypogl., hypoglosal triangle; Med., median, medullary; Ped., peduncle; Sup., superior. (B) Posterior view of the cerebellum. Cer., cerebello; Fiss., fissure; Med., medullary; P.I.C.A., posteroinferior cerebellar artery; Suboccip., suboccipital. (C) Posterior view of the cerebellum. The left tonsil has been retracted superolaterally to expose the surface of the medulla as well as the lateral recess of the IV ventricle. Lat., lateral; P.I.C.A., posteroinferior cerebellar artery; Suboccip., suboccipital. (D) Posterior view of the cerebellum. A dissector is located into the lateral recess. A., artery; Lat., lateral; P.I.C.A., posteroinferior cerebellar artery; Suboccip., suboccipital; Vert., vertebral.

\section{Surgical Technique}

We describe the surgical technique, supporting description of approach with some anatomical specimens performed in laboratory (Figures 3A-D).

The patient is positioned prone with the head placed in a neutral position whereas the cervical spine is slightly anteriorly flexed. Bilateral somatosensory evoked potential and VIII, XI and XII cranial nerves monitoring are performed. A midline vertical skin incision is made from the inion to the second vertebra. A suboccipital midline craniotomy extended to the posterior rim of the foramen magnum is performed. The posterior arch of $\mathrm{C} 1$ is removed, but preserving the atlantooccipital joints.

The dura is opened in Y-like fashion. Cerebellomedullary arachnoid is sharply and meticulous dissected unilaterally to allow mobilization of cerebellum's tonsils off the dorsal surface of the medulla. Opening of the tonsillovermian fissure further increased the exposure. This maneuver allows the access to the inferior end of the IV ventricle and the MO. The medulla enlarged by the intrinsic lesion, is displacing the tonsils upwards. The bulging neural lesion is displacing the posterior inferior cerebellar arteries (PICAs), and the vascular structures are identified and preserved. Regarding veins, the cerebellomedullary fissure vein drains the superior and ventral surfaces of the tonsils and portions of the inferior vermis. It passes laterally within the fissure to empty into the tributaries of the superior petrosal sinus. At its medial origin, the cerebellomedullary fissure veins may communicate by means of the lateral uvular vein with the inferior vermian vein. The posterior aspect of the medulla can be exposed without sacrificing neural tissue. A minimal neural opening is performed in the midline, in the area of less tissular vascularization, known as safe entry zone of the inferior half of the medulla. Removal of small piece of tissue for histopathological study is performed in real time to define the extent of resection. Then, the duramater is closed in watertight fashion. Muscles and superficial tissues are closed in the usual manner (Figures 4A,B). 

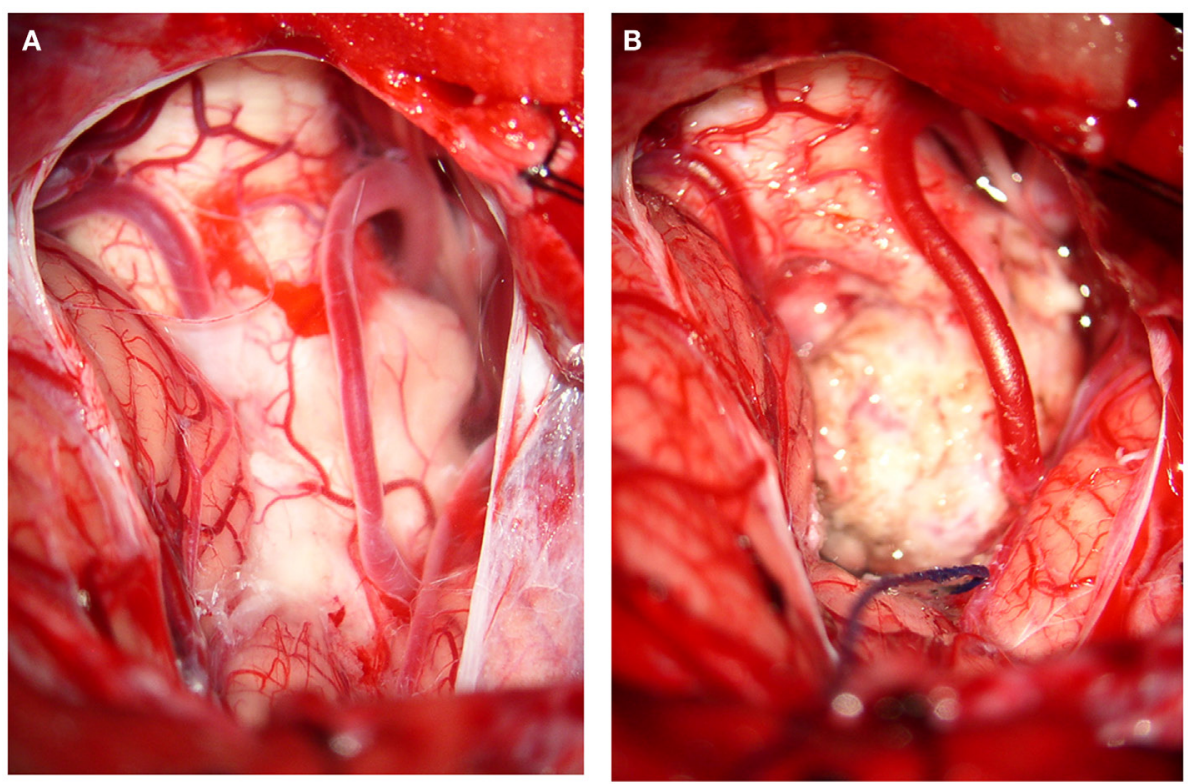

FIGURE 4 | Illustrative images of surgery. Case 1: MO subependymoma. (A) The subtonsillar approach showed the cerebellar vermis and the cerebellar tonsils; dense arachnoidal adherences covered partially the PICAs and also the intrinsic and in part the exophytic MO tumor. (B) After a sharp dissection of arachnoidal adherences, the tumor was completely removed with preservation of both posterior inferior cerebellar arteries (PICAs).

\section{RESULTS}

Two patients with masses located in the inferior half of MO are reported. One was a focal lesion and the other was an exophytic one. The suboocipital subtonsillar midline approach used in these two cases provided a wide surgical view to the foramen of Luschka laterally and up to the middle cerebellar peduncle. It was found that the tumors had produced a mild elevation of the tonsils making the access easier, and there was no need to use retractors. The approach provided enough decompression and simultaneously allowed to obtain histological samples. The extent of resection depended to the intraoperative histopathological findings. Good neurological results were achieved without complications related to the procedure.

\section{DISCUSSION}

Lesions located in the MO represent undoubtedly a difficult challenge, since the expected high risk of surgical exploration of this eloquent area. Moreover, their low incidence in adults combined with little worldwide experience has provided scarce information about surgical results and prognosis. This has probably discouraged the treatment of tumors in this localization for many years.

Although modern neurological imaging techniques provide well-defined images, the histological diagnosis cannot be certainly confirmed. It has been reported that neurorradiological assessment varied from histopathological diagnosis in approximately $40 \%$ of brain stem cases (21-23). Despite the high rate of agreement found between MR spectroscopy and histopathology, there might be a high rate of bias in this location, especially for the partial volume effect of adjacent normal brain tissue and/or cerebrospinal fluid $(8,24,25)$. Therefore, neuroimaging techniques are not so reliable as histological diagnosis, particularly in this area of the brain.

Although stereotactic biopsy is usually safely implemented in other areas of BS such midbrain or pons, pure MO lesions are seldom biopsied (26). For instance, one of the largest last decade series reported 20 stereotactic biopsies of brainstem tumors in children but none for MO (27). We believe that lacks sufficient experience in the literature about stereotactic biopsy in $\mathrm{MO}$ and consequently, it is recommended to discuss case by case. Direct surgery could avoid the potential risks of stereotactic biopsy in this particular area of the CNS.

Regarding the subtonsillary approach, it was originally described to reach the fourth ventricle, and anatomical details have previously reported $(11-15,28,29)$. The access to lesions located in the inferior half of the medulla is particularly wide and safe, with the assistance of intraoperative neurophysiological monitoring. Surgical planning using diffusion tensor imaging and tractography, although not used in the cases reported here, will surely contribute to develop surgical strategies in the near future as evidenced in other eloquent areas of CNS $(30,31)$. The advantages of the dissection of the tonsils over the transvermian approach is that the dissection of the cerebellomedullary arachnoid and the tonsillovermian fissure, allow the preservation of the venous structures specially the cerebellomedullary fissure veins that drains the superior and ventral surfaces of the tonsils and a portion of the inferior vermis. Also, the exposure of the posterior aspect of the $\mathrm{MO}$ does not require the opening of additional neural tissue of the inferior vermis, providing enough room to reach to a safe entry zone in the inferior half of the medulla. It is 
also likely that the extensive arachnoidal dissection decreases the risks of hydrocephalus. Other approach, such as the far lateral suboocipital, should only be considered for lesions located in the anterolateral aspect of MO.

The broader variety of pathological findings that could be found in the MO supports the benefit of getting an accurate histological diagnosis. Regarding the role of intraoperative pathology reviewed in real time, although it can not always confirm the definitive histopathological diagnosis in the operating room, usually provides enough information to determine the extent of resection.

In conclusion, direct surgery via subtonsillar approach assisted by intraoperative neurophysiological monitoring provides a safe surgical way to this critical area of the brain. The awareness of the histopathology is decisive to define the course of treatment and

\section{REFERENCES}

1. Guillamo JS, Monjour A, Taillander L, Devaux B, Varlet P, Haie-Meder C, et al. Brainstem gliomas in adults: prognostic factors and classification. Brain (2001) 124:2528-39. doi:10.1093/brain/124.12.2528

2. Grigsby PW, Garcia DM, Simpson JR, Fineberg BB, Schwartz HJ. Prognostic factors and results of therapy for adult thalamic and brainstem tumors. Cancer (1989) 63(11):2124-9. doi:10.1002/1097-0142(19890601)63:11<2124::AIDCNCR2820631109>3.0.CO;2-9

3. Landolfi JC, Thaler HT, DeAngelis LM. Adult brainstem gliomas. Neurology (1998) 51:1136-9. doi:10.1212/WNL.51.4.1136

4. Guiney MJ, Smith JG, Hughes P, Yang C, Narayan K. Contemporary management of adult and pediatric brain stem gliomas. Int J Radiat Oncol Biol Phys (1993) 25:235-41. doi:10.1016/0360-3016(93)90344-U

5. Shrieve DC, Wara WM, Edwards MS, Sneed PK, Prados MD, Cogen PH, et al. Hyperfractionated radiation therapy for gliomas of the brainstem in children and in adults. Int J Radiat Oncol Biol Phys (1992) 24:599-610. doi:10.1016/0360-3016(92)90704-L

6. Selvapandian S, Rajshekhar V, Chandy MJ. Brainstem glioma: comparative study of clinic-radiological presentation, pathology and outcome in children and adults. Acta Neurochir (Wien) (1999) 141:721-7. doi:10.1007/ s007010050367

7. Rosenthal MA, Ashley DM, Drummond KJ, Dally M, Murphy M, Cher L, et al. Brain stem gliomas: patterns of care in Victoria from 1998-2000. J Clin Neurosci (2008) 15:237-40. doi:10.1016/j.jocn.2007.04.008

8. Salmaggi A, Fariselli L, Milanesi I, Lamperti E, Silvani A, Bizzi A, et al. Natural history and management of brainstem gliomas in adults. A retrospective Italian study. J Neurol (2008) 255:171-7. doi:10.1007/s00415-008-0589-0

9. Bricolo A, Turazzi S, Cristofori L, Talacchi A. Direct surgery for brainstem tumours. Acta Neurochir Suppl (Wien) (1991) 53:148-58. doi:10.1007/978-3-7091-9183-5_25

10. Bricolo A, Turazzi S. Surgery for gliomas and other mass lesions of the brainstem. Adv Tech Stand Neurosurg (1995) 22:261-341. doi:10.1007/978-3-7091-6898-1_5

11. Kellog JX, Piatt JH Jr. Resection of fourth ventricle tumors without splitting the vermis: the cerebellomedullary fissure approach. Pediatr Neurosurg (1997) 27(1):28-33. doi:10.1159/000121221

12. Matsushima $T$, Inoue $T$, Inamura $T$, Natori $Y$, Ikezaki $K$, Fukui $M$. Transcerebellomedullary fissure approach with special reference to methods of dissecting the fissure. J Neurosurg (2001) 94(2):257-64. doi:10.3171/ jns.2001.94.2.0257

13. Jean WC, Abdel Aziz KM, Keller JT, van Loveren HR. Subtonsillar approach to the foramen of Luschka: an anatomical and clinical study. Neurosurgery (2003) 52(4):860-6. doi:10.1227/01.NEU.0000053146.83780.74

14. Gök A, Alptekin M, Erkutlu I. Surgical approach to the fourth ventricle cavity through the cerebellomedullary fissure. Neurosurg Rev (2004) 27(1):50-4. doi:10.1007/s10143-003-0286-5 could avoid the disastrous consequences of empiric treatments in cases appropriately selected.

\section{ETHICS STATEMENT}

All subjects gave written informed consent according to the requirements of the Institute of Medical Research A. Lanari, University of Buenos Aires.

\section{AUTHOR CONTRIBUTIONS}

AR: design of the research, writing of the article, revision of the literature. DH: participation in the design of the research and critical review of the paper. AC: work in the Anatomical Research Laboratory.

15. Kyoshima K, Sakai K, Goto T, Tanabe A, Sato A, Nagashima H, et al. Gross total surgical removal of malignant glioma from the medulla oblongata: report of two adult cases with reference to surgical anatomy. J Clin Neurosci (2004) 11(1):75-80. doi:10.1016/j.jocn.2003.02.007

16. Morota N, Deletis V. The importance of brainstem mapping in brainstem surgical anatomy before the fourth ventricle and implication for intraoperative neurophysiological mapping. Acta Neurochir (Wien) (2006) 148:499-509. doi:10.1007/s00701-005-0672-6

17. Mursch K, Halatsch ME, Markakis E, Behnke-Mursch J. Intrinsec brain stem tumors in adults: results of microneurosurgical treatment of 16 consecutive patients. BrJNeurosurg (2005) 19(2):128-36. doi:10.1080/02688690500145530

18. El-Bahy K. Telovelar approach to the fourth ventricle: operative findings and results in 16 cases. Acta Neurochir (Wien) (2005) 147(2):137-42. doi:10.1007/ s00701-004-0407-0

19. Nishio S, Takeshita I, Fujii K, Fukui M. Brain stem glioma: the role of a biopsy. Br J Neurosurg (1991) 5(3):265-73. doi:10.3109/02688699109005186

20. Kansal S, Jindal A, Mahapatra AK. Brainstem glioma: a study of 111 patients. Indian J Cancer (1999) 36(2-4):99-108.

21. Schumacher M, Schulte-Monting J, Stoeter P, Warmuth-Metz M, Solymosi L. Magnetic resonance imaging compared with biopsy in the diagnosis of brainstem diseases of childhood: a multicenter review. J Neurosurg (2007) 106(2 Suppl):111-9.

22. Rachinger W, Grau S, Holtmannspotter M, Herms J, Tonn JC, Kreth FW. Serial stereotactic biopsy of brainstem lesions in adults impacting diagnostic accuracy compared with MRI only. J Neurol Neurosurg Psychiatry (2009) 80:1134-9. doi:10.1136/jnnp.2009.174250

23. Sanai N, Wachhorst SP, Gupta NM, McDermott MW. Transcerebellar stereotactic biopsy for lesions of the brainstem and peduncles under local anesthesia. Neurosurgery (2008) 63(3):460-6. doi:10.1227/01. NEU.0000324731.68843.74

24. Boviatsis EJ, Kouyialis AT, Stranjalis G, Korfias S, Sakas DE. CT-guided stereotactic biopsies of brain stem lesions: personal experience and literature review. Neurol Sci (2003) 24:97-102. doi:10.1007/s10072-003-0093-3

25. Massager N, Davi P, Goldman S. Combined magnetic resonance imaging and positron emission tomography-guided stereotactic biopsy in brainstem mass lesions: diagnostic yield in a series of 30 patients. J Neurosurg (2000) 93:951-7. doi:10.3171/jns.2000.93.6.0951

26. Kondziolka D, Lundsford LD. Stereotactic biopsy for intrinsec lesions of the medulla through the long-axis of the brain stem: technical considerations. Acta Neurochir (Wien) (1994) 129(1-2):89-91. doi:10.1007/BF01400879

27. Perez Gomez JL, Rodríguez Alvarez CA, Marhx Bracho A, Rueda Franco F. Stereotactic biopsy for brainstem tumors in pediatric patients. Childs Nerv Syst (2010) 26:29-34. doi:10.1007/s00381-009-1000-x

28. Yasargil MG. Microneurosurgery: CNS Tumors - Surgical Anatomy, Neuropathology, Neuroradiology, Neurophysiology, Clinical Considerations, Operability, Treatment Options (Vol. IV A). Stuttgart: George Thieme (1994). p. $86-7$. 
29. Rothon AL Jr. Cerebellum and fourth ventricle. Neurosurgery (2000) 47(Suppl 1):S7-27. doi:10.1097/00006123-200009001-00007

30. Phillips NS, Sandorf RA, Helton KJ, Boop FA, Zou P, Tekautz T, et al. Diffusion tensor imaging of intraaxial tumors at the cervicomedullary and pontomedullary junctions. Report of two cases. J Neurosurg (2005) 103(6 Suppl):557-62.

31. Chen X, Weigel D, Ganslandt O, Buchfelder M, Nimsky C. Diffusion tensor imaging and white matter tractography in patients with brainstem lesions. Acta Neurochir (Wien) (2007) 149(11):1117-31. doi:10.1007/ s00701-007-1282-2
Conflict of Interest Statement: The authors declare that the research was conducted in the absence of any commercial or financial relationships that could be construed as a potential conflict of interest.

Copyright (๐) 2016 Rabadán, Campero and Hernández. This is an open-access article distributed under the terms of the Creative Commons Attribution License (CC BY).

The use, distribution or reproduction in other forums is permitted, provided the original author(s) or licensor are credited and that the original publication in this journal is cited, in accordance with accepted academic practice. No use, distribution or reproduction is permitted which does not comply with these terms. 